\title{
Local control over Aboriginal health care improves outcome, study indicates
}

Published at www.cmaj.ca on Oct. 15

A s officials scramble to explain why Canadian Aboriginal people are especially vulnerable to pandemic (H1N1) 2009 flu, health scientists in Manitoba and British Columbia have compiled striking evidence that First Nations control of health care leads to better health.

The findings, presented at the Canadian Public Health Association conference in Winnipeg, Manitoba, in June, also indicate that federal reluctance to invest in local nursing stations within First Nations communities impairs health outcomes and inflates costs to provincial health budgets.

The lack of intergovernmental coordination and the failure to harmonize federal and provincial health policies are a contributing factor to the vulnerability of Aboriginal people to the pan- demic virus, says the study, Where to Invest, which has been submitted for publication and were being peer reviewed as of Nov. 3.

The study was conducted by a multidisciplinary team from the University of Northern British Columbia, the University of Manitoba, Simon Fraser University in BC and the Assembly of Manitoba Chiefs. It was funded by grants from the Canadian Institutes of Health Research (CIHR) and Manitoba Health. Over the course of the coming year, coauthor Josée Lavoie says the team hopes to "define a basket of essential primary health care services that should be delivered on reserves."

The findings indicate that a Health Canada program to transfer control of health care into First Nations hands is yielding success, despite concerns about financial constraints imposed by the federal government.
But underfunding of on-reserve health services results in First Nations patients travelling to Manitoba's provincially funded urban hospitals to receive care they should be able to access at home, the researchers conclude. "Our results question the overall efficiency of the health care system, which spans federal and provincial jurisdiction, as long as policy decisions may continue to be made by one party while ignoring the impact on the other."

"To some degree communities, researchers and policy-makers believed these things were probably true," says Lavoie, a health policy specialist who launched the study at the University of Manitoba's Centre for Aboriginal Health Research before moving to the University of Northern British Columbia, in Prince George, BC. What's new here is that we have shown this with hard numbers [that] policy makers will have to consider."

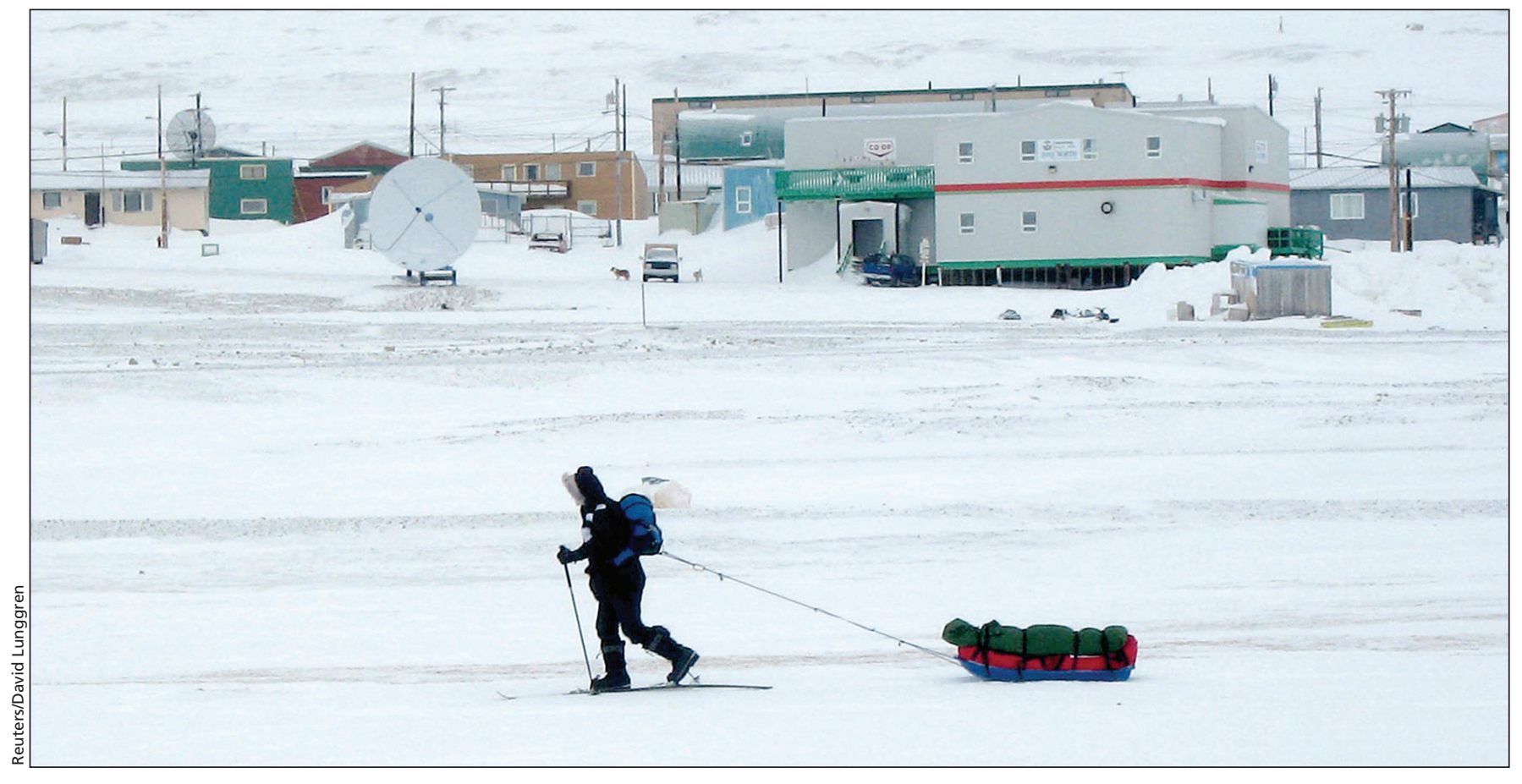

Health policy specialist Josée Lavoie says a research team hopes to "define a basket of essential primary health care services" that should be delivered in remote and rural settlements such as Resolute Bay, Nunavut. Resolute Bay which as was founded in 1953. 
Lavoie's team found that 59 Manitoba First Nations communities with local access to federally-funded nursing stations consistently demonstrated lower rates of hospitalization for Ambulatory Care Sensitive Conditions, ones that can be treated either through local outpatient primary health care interventions or in major health care facilities like hospitals.

The team tracked 29 conditions between 1985 and 2005 and compared rates of admission to hospital. Data from the Manitoba Centre for Health Policy was isolated using postal codes to focus on residents of Manitoba First Nation communities.

In an earlier 2005 evaluation of Health Canada's transfer of control to First Nations communities, Lavoie concluded that while the federal government compelled communities with control of their health services to produce reams of reports, it failed to create an information system capable of helping it decide how to improve health outcomes. That may have cloaked the need for expanded primary care, she stated. "There is currently no mechanism to collate the collected data into information on which to base decisions. The overall picture is that of a patchwork, not a system," (www.umanitoba.ca/centres/cahr/cahr -research/past_research/pastresearch -healthtransfer-english.html).

Lavoie and coauthor Pat Marten's study fills a key gap in health research, says Chris Lalonde, a University of Victoria psychologist who found a relationship between increased Aboriginal control of health services and reduced suicide rates (Mongr Soc Res Child Dev: 2003;68:vii-viii,1-130).

"This is groundbreaking work that is rooted in what has been happening in the communities since they began signing agreements to transfer control," he says, adding that there is a clear message for the federal government. "When First Nations communities have more direct control over health services, health outcomes will improve."

Wayne Warry, an anthropologist at McMaster University in Hamilton, Ontario, concurs. "Local control does a number of good things. It frees com- munities to make decisions and design innovative programs. And when you improve the services, the first thing that happens is people come in for more care."

Malcolm King, scientific director of the Canadian Institute of Health Research's Institute of Aboriginal Peoples' Health, says local control over health care suggests that "the goal of achieving health equity with rural Manitoba is achievable" within a decade.

King adds that the finding that communities in which Ottawa has built primary health care facilities are healthier than those where Ottawa instead airlifts patients to provincial hospitals is significant. "This may seem like it's almost a required conclusion, but it's nice that they have been able to prove it. And I haven't seen it proven before," he says. "You might say it seems obvious, but then you'd have to ask: What's the matter with our governments, that without proof like this, they don't understand the message that to save money on primary health care they first have to invest in it?"

Manitoba Health spokeswoman Julie Kentner says that once the study has been fully reviewed, it could affect plans for health care service delivery in Manitoba First Nations communities.

Health Canada paid \$41.7 million to airlift Aboriginal patients to provincially funded hospitals in 2008, roughly $30 \%$ of Ottawa's $\$ 151$ million outlay for Aboriginal health care within the province.

Assembly of First Nations Public Health Adviser Kim Barker says much of that travel money would be better spent on improving local care. "They've done a lousy job of building local health care capacity."

Health Canada's internal management expenditures are also increasingly seen as a drain on the overall pot of monies available for Aboriginal health spending, a concern which reinforces calls for community control of budgets, Barker adds.

Further compounding the issue is that communities that take responsibility for their health systems have their health budgets essentially frozen under a $2 \%$ increase ceiling that the federal government has imposed on communities that take control of some health care services, Barker says. "In theory, transfer should work to benefit health conditions but there are many severe financial barriers. For instance, a lot of the communities that have transferred control [from Ottawa] no longer qualify for nursing stations."

Yet the study delivers a vital message that nursing stations represent "a good model of primary health care in remote communities," says Kue Young, a University of Toronto epidemiologist specializing in Aboriginal health. "Unfortunately, First Nations communities and their political leadership increasingly view this as secondclass care - that only physicians and hospitals are acceptable, regardless of remoteness or population size."

Young also cautions that data contraints may undermine the study's findings. "The authors actually have not shown that there are no pre-existing health status differences among the communities."

Smylie also worries about data quality. "I have a bit of an allergy to using postal codes for an Aboriginal ethnic identifier," she says. "It could actually be community size, community location, or community economics that predicts the health outcomes and not the type of health service."

John O'Neil, one of the study's coauthors and head of the Health Sciences Faculty at Simon Fraser University in Vancouver, BC, says comparing health outcomes among communities that opt for varying degrees of local control "is an incredibly complicated methodological problem. It's been addressed as carefully as possible in this study. But are we looking at a selfselected group of communities who have taken control? To be frank, I don't know if we can answer that. It's a limitation."

Lavoie and O'Neil are currently working with the BC First Nations Health Council to mount a provincial study to test whether the Manitoba results can be generalized to other provinces. - Paul Webster, Toronto, Ont.

DOI:10.1503/cmaj.109-3072 